\title{
A Touch of Paint: Transgressing Unspoken Boundaries
}

\author{
Kim Atkinson
}

Kim Atkinson is an early childhood educator and a pedagogical facilitator with the University of Victoria's Unit for Early Childhood Research and Development. She also co-coordinates, with Danielle Davis, the Images of Learning Project—an exhibit, blog, and series of presentations that highlights the work of ECEs and the competencies of children (www.imagesoflearningproject.com). Email: klatkins@uvic.ca

Contemporary early childhood contexts are rife with unspoken rules, boundaries, and expectations that are understood to be best practice within discourses of quality in early years settings. These habitual practices are not apolitical: They flow from powerful discourses purporting to be scientific and reliable, with systematically defined ways of thinking, seeing, and speaking about children. Drawing on a body/ paint/brush/forest encounter, the author looks to disrupt these discourses and transgress unspoken boundaries. By engaging with an ethic of resistance, acknowledging the relationality of early childhood practice and the entanglements of human and nonhuman forces, the author seeks to transgress fixed identities and be open to otherness in an ongoing process of becoming.

Keywords: early childhood, quality, pedagogy of listening, relationality

dab would land daringly on a child's cheek or nose, always scrubbed away by pick-up time. Children did not paint on adult faces. eight toddlers experiment with paint, brushes, and paper, all of which are placed among the trees, sand, and logs. Red, yellow, and green paint are held within small shells placed on stumps. The children dab the brushes into the paint, watching as globs of colour adhere to bristles. They touch the brushes to the paper, to the stump, to the logs, noticing the colourful traces that are left. Micah comes toward me with his paintbrush, looking at me with great seriousness. His brush holds a gleaming glob of green paint. He slowly, slowly lifts the brush to my face and very carefully touches it to my nose. The paint stays on my skin, at first cool and wet, later drying to a crusted second skin.

This moment in the forest of paint, brush, and two human bodies stayed with me for days afterward, as though the paint had touched me in ways that were more than skin deep. In my 35 years of working as an early childhood educator, never had a child deliberately painted my face. Or should I say, I have never allowed a child to paint my face. The allowable intersections of paint, children, and adults had always been clear: Paint stayed on paper, sometimes travelling to children's hands and arms. Occasionally a

On a damp day in the forest I am sitting on a stump watching as

The boundaries of where paint could and could not go were never discussed among my colleagues and myself. They were unspoken but nonetheless understood. Paint was something to be contained, and was offered in ways that made this clear. Paint was presented in small containers, in small amounts, with paper placed invitingly alongside. Smocks were offered, and the table was protected with paper or plastic. Cloths were placed close by to wipe up spills, and a wash tub was nearby to clean hands. Without any words spoken, the message was resoundingly clear: Paint had the potential to become unruly, but we would keep it under control.

Not only did we want to keep paint under control, we had a specific agenda for paint. Paint was offered in particular ways that would facilitate particular skills and outcomes, such as sensory experience, fine motor skills, self-expression, and colour mixing. As educators, we viewed both the children and the paint through this narrow lens and had clear expectations of the "right way" to "do" paint. Not only would the potentially unruly paint remain under control, we would also control the children's ways of being with paint. Paint/child/table/ brush/paper interactions would remain predictable, stable and never uncomfortable.

Unspoken agendas and boundaries permeated much of our dailyness with children, and flowed from educators' mutual understandings of what constituted best practice. Creating centres with blocks, books, dolls, and cars, gathering for circle time and snack time, taking trips to the pumpkin patch in October, singing songs about pussy willows in April-all these proceeded year by year unquestioned. We had expectations of how children should act and strategies and language we used when children did not act as we thought they should. Phrases such as "walking feet," "use your words," and "wait your turn" were habitual, as were demands to sit "criss cross" and "shake your wiggles out." No one discussed the "rightness" of these phrases, they simply were. 


\section{Developmentally Appropriate Practice as Quality}

In working with these unspoken ways of doing, educators adhered to established conceptions of best practice and quality based on theories of developmentally appropriate practice (DAP). Within these theories, children are viewed as inferior, immature, incomplete, and in need of prescribed knowledge delivered by adults. Activities are valued for the particular skills children will learn — skills deemed necessary for children to become the right kind of adult. For example, the operations guide for a drop-in program funded by the $\mathrm{BC}$ government posits that art activities

encourage children to express emotions, plan and follow through on plans, make representations of their thoughts and ideas, and problem-solve. When children are creating, they are learning about symbolic representation, an important element of emergent literacy and numeracy. The early symbolic representation in art can help to lay a firm foundation for future academic learning. For younger children, adults can use hand-over-hand strategies to help their young children enjoy using the materials. (StrongStart BC Early Learning Programs, n.d., p. 46)

The implicit message is that engaging in artistic processes is valuable only for the developmental goals that can be achieved and to prepare children for future academics. Younger children are seen as incapable of enjoying materials without adult intervention, and learning outcomes are measurable, static, and applicable to all children regardless of their context or community. Within this discourse, quality is defined as the application of a universal set of norms, which, as Lenz-Taguchi (2008) tells us, provide universally determined stages of development that have become entrenched as truth:

Formulated within the discipline of developmental psychology, these ideas about universal, age-related stages have produced widely held "truths" about children's development and learning. These truths have been translated into accepted practices, often collectively called developmentally appropriate practice (DAP), designed to educate and normalize children into healthy, enlightened, and free citizens. (p. 271)

Within this framework of DAP, children are viewed through a particular lens of what is deemed "normal development" and are thus classified, judged, instructed, and "fixed" if they are found to not fit the norm. Children are offered particular types of experiences based on developmental needs, and they are expected to take on those experiences in "normal" ways. The role of the educators is clear: to be knowledgeable about developmental norms and to implement programs and strategies that foster normal growth and development. Noting how developmental theories have come to dominate perceptions of childhood, MacNaughton (2005) observes that this perception has "settled so firmly into the fabric of early childhood studies that its familiarity makes it just seem 'right', 'best' and "ethical"” (p. 1). In these "right," best," and "ethical" ways of doing early childhood, there are unspoken understandings as to how paint is offered and what children can do with it. Both paint and children are bounded by these unspoken understandings, this normalizing lens that prescribes particular ways of being and doing. To fall outside this normalizing lens is to fail at "normaliz[ing] children into healthy, enlightened, and free citizens" (Lenz Taguchi, 2008, p. 271). Clearly there is no room for a child to touch paint to an educator's nose.

\section{Quality as Political}

These established notions of childhood purport to be scientific, rational, and reliable (Dahlberg \& Moss, 2005) and have been taken up by policy makers and governing bodies in determining what constitutes quality childcare. Subjectivity and local knowledges are put aside, and "objective" technical measures are put in place to assess outcomes and prescribe "one size fits all" norms. Standards and regulations are routinely enacted to ensure that practice conforms to DAP. Dahlberg and Moss (2005) tell us of the multitude of technologies used to ensure standardization:

Measuring quality is just one of a variety of technologies deployed to regulate practice in preschools. Preschools are increasingly bounded by other normalising frameworks - either required by government or offered by experts: standards, curricula, accreditation, guidelines on best practice, inspection, audits, the list rolls on. Like quality, these guides to technical practice purport to provide decontextualised "benchmarks"- generalisable standards - of what is necessary or desirable. What these normalising technologies have in common is an administrative logic, an intention and capacity to govern more effectively by ensuring that correct outcomes are delivered. (p. 9)

The "correct outcome" is ensuring that children progress through normal developmental stages, a narrowly structured set of standards that progress in linear, stable, and predictable increments. Embedded in this theory is the understanding that learning takes place within individual children, and that the knowledges and abilities valued within DAP are neutral and applicable to all children in all contexts 
(Lenz Taguchi, 2011). These very powerful "truths" of children's development are used in constructing programs and policies, and they sanction right and wrong ways of thinking, talking, and doing early childhood.

Childcare services continue to expand internationally with more children in care for longer periods of time, thus generating greater interest and scrutiny as to what kind of care and education is desirable. Childcare services are perceived as key to a creating a competitive economic advantage, not only by enabling parents to work, but also by inculcating young people with the right kind of education with defined outcomes that will benefit a future economy (Dahlberg \& Moss, 2005). Governing bodies globally are focusing on policies, provisions, and investment that will result in economic benefits and secure a stable social order (Dahlberg \& Moss, 2005; Osgood \& Giugni, 2015). Scientific knowledges that claim to "know" children and offer prescriptive and reliable models of achieving a desired end (the right kind of adult) are appealing to government bodies whose agendas include "objective truths" and predetermined outcomes. Thus DAP is more than simply an apolitical set of guidelines for practice with young children: It is a highly political agenda that offers organizations and government agencies scientific, orderly, and stable responses to questions of what we want a child to become. Osgood and Giugni (2015) suggest that

excellence in the early childhood context is reduced to the production and cultivation of normative development in childhood so that the young children of today will become the worthy citizens of tomorrow to ensure global economic advantage. So it becomes very clear that far from being apolitical and commonsense the top-down imposition of quality through curriculum, assessment, inspection, regulation - and other disciplinary technologies (to borrow from Foucault) is deeply political and driven by economic imperatives. (p. 3)

Not only are normalizing theories of DAP deeply political and driven by economic imperatives, they are implicit in the ongoing project of settler colonialism. Euro-Western knowledges that value scientific truths and predictable linear development that universalize children continue to dominate Canadian practice and thinking about childhood (Nelson, Coon, \& Chadwick, 2015). These practices are embedded into early years pedagogy in which colonial assumptions of humancentrism, of categorizing and controlling for the benefit of the colonizer are taken for granted (Nelson et al., 2015). Early childhood education becomes "a site in which we all learn to participate in the logic of colonialism" (Clark, Pacini-Ketchabaw, \& Hodgins, 2014, p. 753).

The forest where Micah and I sat with paint appears idyllic and is in keeping with the current trend of taking children into nature to encourage social and environmental responsibility (Nxumalo, 2014; Pacini-Ketchabaw, 2013). However, these lands are the traditional territories of the Coast and Straits Salish and Lekwungen peoples, and they hold histories and stories that have been silenced, stories of displaced people, of conquest, of violence (Nxumalo, 2014; Pacini-Ketchabaw, 2013).

The paint Micah and I use is equally implicated, because histories of paint are entangled with colonizing practices of categorizing art and identifying what counts as "art." Art has had a social function in perpetuating colonialism by depicting and romanticizing the dying Indian, the noble savage, and the unknown, uninhabited wilderness (Clark et al., 2014).

Unspoken assumptions of best practice perpetuate the idea that a single story of childhood exists. That story is imbued with EuroWestern values that systematically define ways of thinking, seeing, and speaking about children. Quality is understood as a set of universal understandings that can be applied to all children, educators, and settings. These understandings purport a very particular view of the world and very particular truths. Unspoken agendas and mutual understandings of what constitutes best practice are not innocent: They are laden with colonial values and political intentions.

\section{Critical Reflection and Challenging the Status Quo}

What possibilities are there to challenge these highly valourized theories? How might we begin to invite multiple stories of children and educators, stories that are diverse, complex, nonlinear, and often messy? How might we shift our pedagogies away from prescriptive outcomes toward a recognition of entangled relations, of stories past and present? How do we resist notions of child/forest encounters as idyllic and begin to invite more complicated conversations about the ethics and politics of our presence in the forest (Pacini-Ketchabaw, 2013, p. 363)? How might a moment with a touch of paint create a rupture in our unspoken assumptions?

As Micah approached me with the paintbrush on that day in the forest, my mind was flooded with a rush of questions, uncertainties. Should I allow this? As he raised the paint-filled brush to my nose, my body tensed, instinctively wanting to shrink backwards, away from the brush. But as the brush neared my nose, I was aware of a pull, a connection within the adult/child/brush/paint/forest assemblage, a dynamic force that could not be contained within a prescriptive theory. The familiar became unfamiliar, and something new and 
unexpected was produced.

Resisting the status quo of developmental frameworks and Euro-Western assumptions requires that we be inspired by difference, letting go of fixed habits of seeing and doing and opening spaces for the yet-to-be-known. It means acknowledging the relationality of early childhood practice, the rich and varied entanglements of human and nonhuman forces that circulate in an ongoing process of becoming.

But how to do this? What processes might we engage with to begin a shift away from our conventional ingrained practices? We can begin by critically reflecting on why we do what we do, scrutinizing our ways of thinking and our values, unpacking our understandings to reveal our taken-for-granted assumptions. Lenz Taguchi (2008) terms this process deconstructive talk and suggests that it is not about replacing one understanding with another, but being open to difference:

In the context of ECE practice ... deconstruction is about purposeful disruptions, destabilizations, undermining, and challenges to taken-for-granted notions, values, practices, and pedagogy-as-usual (Lenz Taguchi, 2000, 2006a, 2006b). Difference, in this context, is something to be actively used as a productive force, rather than as a threat to consensus or a problem to overcome. (p. 272)

In that moment with a boy and a paintbrush, there was a temptation to simply wipe the paint off my nose, to wipe away the traces of green, and in doing so wipe away the questions and uncertainties. But, having perceived a disruption, I could not let it go. I needed to hold onto that moment with paint and place it alongside taken-for-granted pedagogy. By actively attending to the moment of difference, the unspoken assumed meanings of paint began to crumble.

\section{A Pedagogy of Listening: Creating Space for Difference}

Challenging our pedagogy-as-usual means letting go of certainty. It means shifting away from known identities, abandoning images of the educator as expert and children as knowable subjects. Most crucially, it means we have an ethical responsibility to listen. Listening in this context is not a tokenistic gesture, but is about being open without reservation to what is heard. Bronwyn Davies (2011) uses the term open listening and explains:

The philosophy and practice of open listening that I am developing here is not just about being nice or tolerant, and nor is it the kind of listening that looks for the repetition and affirmation of the already known. Open listening "requires a suspension of our judgments and above all our prejudices" (Rinaldi, 2006 , p. 65). But more than this, it means opening up the ongoing possibility of coming to see life, and one's relation to it, in new and surprising ways. Open listening might begin with what is known, but it is open to the understandings one has of self and other, and the relations between them, creatively evolving into something new. Open listening opens up the possibility of new ways of knowing and new ways of being, both for those who listen and those who are listened to. (p. 1)

Working within a pedagogy of listening means that we as educators are open to children's thinking, their wonderings, their theories. It means treating what we hear with respect for "otherness," such that we do not try to fit what we hear into a neat category or dismiss it as invalid, untrue, or without value. To be open to the Other demands that we struggle to make meaning, to resist marginalizing, ignoring, or "cutesifying" what we hear.

Listening is central to the pedagogy of Reggio Emilia and is understood to be complex and intensely relational. As we listen we must suspend our judgment and assumptions and be open to curiosity, doubt, and new questions. This is not easy, and not without risk. Our habits of classifying and normalizing children with prescribed outcomes so as to "know" them are easy to fall into. There is a danger that listening can be used a tool to "know," to maintain the status quo. To confront the powerful discourse of development theories, we must work with an ethic of resistance to disrupt what we take for granted and make conscious choices for practice driven by our sense of responsibility to our new understandings of ourselves, our work, and the children (Lenz Taguchi, 2008). Carlina Rinaldi (2001), president of Reggio Children and a professor of pedagogy at the University of Modena and Reggio Emilia (Italy) says:

Listening is not easy. It requires a deep awareness, and at the same time a suspension of our judgements, and above all our prejudices; it requires openness to change. It demands that we have clearly in mind the value of the unknown and that we are able to overcome the sense of emptiness and precariousness that we experience whenever our certainties are questioned. (p. 81)

With a touch of paint on my nose from a small boy with a paintbrush, conventional boundaries, fixed identities, and truths were transgressed. A different reality emerged: a reality where the normative rules, assumptions, and knowledges were displaced and 
something new was created. I was not the same as before the brush touched me. I could not go back to who I was before. Davies (2011) tells us that listening, in this sense,

involves opening oneself to an ongoing process of what Deleuze (1994) named differentiation, that is, to becoming other to oneself, and to a process of evolution that takes the self beyond what it already knows. (p. 1)

These openings or "moments of grace" (Davies, 2011) might give us the impetus to become more aware of who and what we are, where we believe ourselves to be, and who and what we might become (Lenz Taguchi, 2008).

\section{Entangled Relations: Attending To the In-Between}

In that moment in the forest, the child and I were not the only participants. The brush, the glistening paint, the coolness and silence of the forest air, the stump on which I sat, the uneven ground beneath the child's feet.... all these were inextricably entangled, flowing among and through the moment, inspiring particular ways of being.

Conventional perspectives of children's learning are solidly based on the individual child. Children, indeed all of us, are considered separate from objects, ideas, practices, and place. The assumption is that learning is an individual process taking place within individual children. Developmental theories rest on this understanding and identify specific knowledges children should have at specific ages, no matter what their environment.

These perspectives are predicated on the assumption that books, toys, routines, expectations of behaviour, rules, sounds, furniture, the kind of language used by adults in conversations and songs - all of this - has no bearing on learning or on what children do. However if we shift our focus away from the child and attend to the environment, the space, the codes of practice, the bodies and materials, we can begin to notice how all of these are entangled, each acting on the other, interconnecting, transforming, and being transformed. Different materials invite different engagement; they have meaning, they evoke ways of doing ... they are not passive. Paint held within a shell on a stump beckons us, calling to each of us in different ways, and we cannot predict the movements, directions, or possibilities that might emerge. Lenz Taguchi (2011) tells us:

Thus, thinking and learning is always an encounter; something that "hits us" as we engage with the world (Bennett, 2001). Thinking and learning takes place in between heterogeneous actors, rather than being something localised inside a human superior mind separated and located above the material world and other organisms. "Something in the world forces us to think. This something is an object not of recognition but of a fundamental encounter" (Deleuze, 1994, p. 139). (p. 46)

By attending to what happens in-between children/adults/paint/brush/forest/stump we are able to notice differently. We are pushed beyond our taken-for-granted ways of seeing to see something unknown, new. We might notice the forces, flows, gestures, time, movement, the glistening, the smooth, the damp, the intensities, how all of these move and bounce and tumble, interacting, transforming, and becoming.

By engaging with the world in this way, by noticing differently and embracing the unknown, we transcend the unspoken boundaries of "best practice." In transcending these unspoken boundaries, we are rupturing the status quo of universalizing childhood, normalizing frameworks, and unspoken agendas. Within this rupture, this crack, we can begin to listen. We might listen for stories of place, of histories, of people and animals and stumps and shells and paint. And perhaps we might begin to tell new stories of childhood, stories that are diverse, relational, complicated, and always shifting.

The touch of paint on my nose surprised me with its coolness, its gentleness. Micah moved back to the stump, dabbed his brush into the paint and returned to me, this time to touch my hand. He carefully stroked my palm with the brush, making criss-crossing lines. The paint felt different on my hand than on my nose. Yet was that true? Maybe it felt more "normal" to have paint on my hand than on my nose. Maybe it was me that was different, and not the paint. The blob of paint on my nose had blurred conceptions of normal. Unspoken boundaries had been transgressed; fixed identities had been ruptured. I cannot turn away from these transgressions and ruptures, but must ask instead, how might I remain open to otherness in an ongoing process of becoming? 


\section{References}

Clark, V., Pacini-Ketchabaw, V., \& Hodgins, D. (2014). Thinking with paint: Troubling settler colonialisms through early childhood art pedagogies. International Journal of Child, Youth, and Family Studies, 5(4.2), 751-781.

Dahlberg, G., \& Moss, P. (2005). Ethics and politics in early childhood education. New York, NY: Routledge.

Davies, B. (2011). Open listening: Creative evolution in early childhood settings. International Journal of Early Childhood, 43(2), 119-132. doi: 10.1007/s13158-011-0030-1

Lenz Taguchi, H. (2008). An "ethics of resistance" challenges taken-for-granted ideas in Swedish early childhood education. International Journal of Educational Research, 47, 270-282.

Lenz Taguchi, H. (2010). Going beyond the theory/practice divide in early childhood education: Introducing an intra-active pedagogy. London, England: Routledge.

Lenz Taguchi, H. (2011). Investigating learning, participation, and becoming in early childhood practices with a relational-materialist approach. Global Studies of Childhood, 1(1), 36-50.

MacNaughton, G. (2005). Doing Foucault in early childhood studies: Applying poststructural ideas. London, England: Routledge

Nelson, N., Coon, E., \& Chadwick, A. (2015). Engaging with the messiness of place in early childhood education and art therapy: Exploring animal relations, traditional hide, and Drum. Canadian Children, 40(2), 43-56.

Nxumalo, F. (2014). Unsettling encounters with "natural” places in early childhood education (Doctoral dissertation). Retrieved from: https://dspace.library.uvic.ca/handle/1828/5772

Osgood, J., \& Giugni, M. (2015). Reconfiguring "quality": Beyond discourses and subjectivities to matter, bodies, and becomings in early childhood education. In G. S. Cannella, M. Salazar Pérez, \& I. F. Lee (Eds.), Critical examinations of quality in childhood education and care: Regulation, disqualification, and erasure. New York, NY: Peter Lang.

Pacini-Ketchabaw, V. (2013). Frictions in forest pedagogies: Common worlds in settler colonial spaces. Global Studies of Childhood, $3(4), 355-365$.

Rinaldi, C. (2001). Documentation and assessment: What is the relationship? In Project Zero and Reggio Children: Making learning visible: Children as individual and group learners. Reggio Emilia, Italy: Reggio Children

StrongStart BC Early Learning Programs. (n.d.). Operations guide. Retrieved from: http://www2.gov.bc.ca/gov/content/educationtraining/administration/kindergarten-to-grade-12/early-learning/strongstart-bc 